\title{
La guerra entre México y los Estados Unidos en la novela El fistol del diablo, de Manuel Payno
}

\author{
Roberto Cantú \\ California State University, Los Angeles \\ rcantu@exchange.calstatela.edu
}

RESUMEN: El presente ensayo plantea tres planos de análisis para un mejor entendimiento de la novela El fistol del diablo, de Manuel Payno. En primer lugar, las contribuciones de Payno al desarrollo de la novela histórica en México, ante todo en el tratamiento novelístico de la guerra entre México y los Estados Unidos en 1846-1848 (el núcleo principal de la novela); en segundo lugar, los cambios de orden y exclusión de capítulos y de enlaces narrativos en El fistol del diablo a lo largo de sus tres ediciones, algo que nos lleva a proponer que de las tres novelas de Payno, la de mayor aparente importancia para el autor fue $\mathrm{El}$ fistol del diablo, manteniéndolo ocupado en varias ediciones a lo largo de más de cuarenta años. En tercer lugar, se plantea una lectura de El fistol del diablo en nuestras circunstancias históricas — por ejemplo, la guerra de ocupación de los Estados Unidos en Irak y Afganistán - sosteniendo que tal lectura crítica no puede limitarse a cuestiones meramente literarias, ya que paralelos históricos de ocupación militar pueden ser fuentes de una mejor comprensión de novelas históricas tales como El fistol del diablo.

Aвstract: This essay proposes three levels of analysis for a better understanding of the novel El fistol del diablo, by Manuel Payno. First, the contributions of Payno to the development of the historical novel in Mexico, above all in the novelistic treatment of the war between Mexico and the United States in 1846-1848 (the principal focus of the novel); second, the changes of order and deletion of chapters and narrative links in El fistol del diablo throughout its three editions, something which leads us to propose that of the three novels by Payno, apparently that of most importance for the author was El fistol del diablo, keeping him occupied in various editions across a span of more than forty years. Third, a reading of El fistol del diablo is grounded in our own historic circumstances - for example, the war of occupation by the United States in Iraq and in Afghanistan - maintaining that such a critical reading cannot limit itself to merely literary questions, since historical parallels of military occupation may be sources for a better comprehension of historical novels such as El fistol del diablo.

Palabras clave: la Quinta de San Jacinto, Batalla de Churubusco, Pastor Fido, Tenochtitlan, El Álamo, Antonio López de Santa Anna, el batallón de San Patricio, el Tratado de Guadalupe Hidalgo. 
KeYwords: la Quinta de San Jacinto, The Battle of Churubusco, Pastor Fido, Tenochtitlan, El Alamo, Antonio López de Santa Anna, the San Patricio batallion, the Treaty of Guadalupe Hidalgo.

Se hace cada día más difícil leer la obra de escritores mexicanos del siglo XIX, particularmente la de Manuel Payno, quien escribió novelas larguísimas, de costumbres novohispanas en proceso de desaparecer, con enredos amorosos ligados por fuerza de hábito al romanticismo de su época y que la crítica literaria suele juzgar con desdén. Luis González Obregón, por ejemplo, opina que la narrativa de Payno es descuidada, incorrecta y de pocas luces. ${ }^{1}$ Antonio Castro Leal, por su parte, juzga que la prosa de Payno es de un lenguaje limitado pero ameno debido a su sencillez. ${ }^{2}$ Aurelio de los Reyes, quien representa una prometedora generación crítica en torno a Payno, sostiene que El fistol del diablo es una novela de aprendizaje e imitación de modelos extranjeros, "con una estructura menos consistente" y que "ha ameritado escasa atención". ${ }^{3}$ Carlos Fuentes, como novelista y crítico, es más categórico en su evaluación negativa:

Las novelas del siglo XIX son apenas un suspiro en medio del vendaval histórico [...] La solera aventurera de Manuel Payno en México (Los bandidos de Río Frío, 1888-1981). Y una novela por Vicente Riva Palacio de título más inventivo que su contenido: Monja y casada, virgen y mártir. En ese orden (2011: 76).

La vanguardia en las artes del siglo xx nos ha alejado de los fundadores de la literatura mexicana, generación que asociamos con una estética

\footnotetext{
${ }^{1}$ Ver el prólogo de Luis González Obregón (1992) de donde citamos: "Payno había sido descuidado en la forma, incorrecta hasta lo inverosímil hasta incurrir en faltas ortográficas [...] ayuno de oscuras exquisiteses académicas" (ix).

${ }^{2}$ Consultar el prólogo de Antonio Castro Leal en Manuel Payno (2001) del que entresacamos la siguiente cita: "a pesar de sus abundantes mexicanismos, pobre de léxico y poco variada en recursos sintácticos [...] esa misma naturaleza conversable de su estilo le da a su prosa, si no elegancia ni decoro, una cierta fluidez sencilla y amena" (xii).

${ }^{3}$ Leer el prólogo de Aurelio de los Reyes en Manuel Payno (2000a: 11). En palabras de De los Reyes: "[El fistol del diablo es una] culminación asimismo de un conjunto de ejercicios narrativos, que muestran con claridad el proceso de un doble aprendizaje: el del oficio de escribir mediante el ejercicio de varios géneros literarios...para llegar a la novela larga, y el de crear una literatura nacional" (16).
} 
de realismo ingenuo y tramas de escaso nivel intelectual o artístico. El estilo narrativo de Manuel Payno, sin embargo — con frecuencia tildado de mero costumbrismo- surge de una tradición literaria con elementos formales en embrión de innegable afiliación a la modernidad. ${ }^{4}$

Manuel Payno escribió tres novelas: El fistol del diablo (1845-1848), El hombre de la situación (1861), y Los bandidos de Río Frío (1891), en las que se ilumina el México del siglo XIX, trazando en la jerarquía de sus personajes y rebuscadas tramas la gestación republicana en el país, con sus tradiciones en conflicto, su sangrienta historia independiente - marcada por guerras civiles, invasiones y varios ideales políticos- y sus planes de desarrollo ligados a la modernidad. Como muchos otros escritores de su tiempo, Payno publicó novelas ofrecidas al público por entregas o en diarios en forma de folletín, de lectura necesariamente interrumpida, continuada a través de largo tiempo y abonada por el suspenso y la curiosidad del lector. Aparte de sus reconocidos valores históricos y culturales, la narrativa de Payno merece nuestra atención a un nivel artístico - es decir, como obra de ingenio, de facultad discursiva, de inteligencia en su vasta e intrincada concepción. No cabe duda, Payno es un "fundador" con quien la crítica literaria ha sido por lo general severa. Comentando la obra narrativa de Vicente Riva Palacio, Carlos Monsiváis propone una lectura más acorde con los fines artísticos y pedagógicos de los novelistas del siglo XIX en México:

El folletín, el artículo político y la crónica apuntalan el proceso que desatan la secularización y el salto tecnológico de las prensas manuales a las rotativas. Así, el proceso centrado en la idea de la lectura como apren-

${ }^{4}$ De acuerdo a Harvey L. Johnson, en la novela corta Atenea, de Ignacio Manuel Altamirano, "hay cualidades que asociamos con la novela modernista"; luego ańade: "Clemencia, la primera novela moderna de México por sus cualidades literarias y su concepción estética, es una historia sentimental de trama sencilla cuya acción se remonta a la época de la intervención francesa”, en Altamirano: 15. Hacemos notar las cualidades que Johnson busca en la literatura modernista, que entendemos en relación a la vanguardia más que a la enarbolada por Rubén Darío y su generación: "notables por la corrección de su estilo y la mesura de su construcción" (14). Sabemos hoy día que el estilo y la mesura no son las únicas categorías que definen el modernismo o vanguardia literaria; tales juicios nos alientan en nuestra convicción de que hay nexos entre la literatura mexicana del siglo xIx -ante todo, El fistol del diablo- y la moderna a un nivel formal e ideológico, es decir, en su trinitaria dimensión crítica, irónica y artística en la composición del relato. 
dizaje del sentido de la realidad, afecta en una u otra medida a burgueses y pequeñoburgueses, a señoras de su casa y artesanos, a profesionistas y empleados públicos. Si el analfabetismo es problema mundial - [...] en 1870 uno de cada mil mexicanos tiene acceso a la lectura- la novela de folletín cumplirá un cometido triple: $a$ ) rodear de atractivos inesperados a la alfabetización, $b$ ) ser ocasión de reuniones familiares, gremiales, vecinales, y $c$ ) entretener mientras politiza (y viceversa). ${ }^{5}$

Los novelistas mexicanos del siglo XIX no fueron, en su mayoría, escritores de profesión dedicados por completo a sus labores literarias. Casi todos participaron en guerras civiles o contra ejércitos invasores. No obstante, lo más preciado de la narrativa del siglo xix surgió de la vida política de México — agitada, hondamente partidaria, de incondicionales rencores fratricidas - resultando en una novelística cuyo pulso aún se siente en las mejores novelas de Mariano Azuela, Agustín Yáñez y Carlos Fuentes, es decir, en diferentes generaciones literarias en la historia moderna de México.

Boris Rosen Jélomer nos informa que Payno publicó El fistol del diablo por entregas durante los años 1845-1846 en la Revista Cientifica y Literaria de México, publicación que fue interrumpida durante la guerra con los Estados Unidos. En los primeros meses de 1848, Payno continuó la publicación de El fistol del diablo en el diario El Eco del Comercio, del cual Payno era director y editor (Payno 2000a: 9). ${ }^{6}$ En su investigación y lectura de las diferentes ediciones de El fistol del diablo, Aurelio de los Reyes señala que a partir de 1848 —es decir, durante la última etapa de la guerra contra los Estados Unidos- la escritura de El fistol del diablo perdió su coherencia interna (en particular, las historias de Teresa, Manuel y de Celeste), a consecuencia de estar "mezcladas con la política" (Payno 2000a: 15).

Pese a su evidente interés a nivel de hipótesis, el plan original de Payno no tuvo por qué descarriarse como proyecto literario. Al contrario, el intento por parte de Payno de representar en su novela el desastre na-

\footnotetext{
${ }^{5}$ Ver el prólogo de Carlos Monsiváis en Riva Palacio: 26-27. Énfasis nuestro.
}

${ }^{6}$ Véase también el "Prólogo" de Aurelio de los Reyes (Payno 2000a: 13). 
cional ocurrido en la capital de México a partir de la ocupación norteamericana, indudablemente le obligó a reflexionar y conceptualizar su obra como novela histórica. De interés crítico, por lo tanto, no es la fidelidad de Payno hacia el plan original que supuestamente tuvo al escribir El fistol del diablo, sino el hecho de que se haya pasado toda una vida puliendo y ampliando su primera novela. Sabemos que en 1859-1860 Payno revisó de nuevo El fistol del diablo y la publicó en siete volúmenes, correspondiendo a la primera edición. Hubo una segunda edición en 1871 (cuatro volúmenes), seguida de la tercera y última edición en 1887 (dos volúmenes) publicada mientras Payno desempeñaba el cargo de cónsul de México en Santander, Barcelona y París. ${ }^{7}$ De acuerdo a Rosen Jélomer, la tercera edición tiene "cambios significativos":

En esta ocasión Payno excluyó los últimos ocho capítulos de la primera edición, sustituyéndolos por veinticinco nuevos capítulos (XL-LXIV) y un epílogo. Cambió el orden y los títulos, introduciendo diversos enlaces. Además, incluyó un glosario de "palabras y alocuciones que no han sido todavía aceptadas por la Real Academia Española" que aparecían en el texto, más una extensa introducción (40 páginas) firmada por Pastor Fido (Payno 2000a: 10).

De lo anterior nos interesan tres detalles: en primer lugar, cada edición de El fistol del diablo coincide con un evento o condición nacional de importancia histórica: la guerra contra los Estados Unidos (a partir de 1848, el núcleo principal de la novela); la Guerra de Reforma; la presidencia en crisis de Benito Juárez; y la extendida presidencia de Porfirio Díaz, con síntomas de una emergente dictadura en el país. No cabe duda que Payno llegó a pensar en su primera novela como una alegoría política para reflexión y entendimiento de sus lectores, entreteniéndo-

\footnotetext{
${ }^{7}$ Sabemos que Ignacio Manuel Altamirano fue nombrado cónsul general en España en 1889, y luego cónsul general en Francia con residencia en París, precisamente mientras Payno escribía su última novela, Los bandidos de Río Frío y desempeñaba cargos diplomáticos en Barcelona, Santander y París. Altamirano muere en Italia en 1893, por lo tanto Payno y Altamirano estuvieron próximos uno al otro entre 1889-1892, tres ańos de premura creadora y posibles diálogos entre novelistas, ahora a un paso de la muerte. Los tiempos habían cambiado para ambos escritores. En 1861, Altamirano pide la cabeza de Payno en el Congreso Mexicano; en 1871, ambos fundan un periódico: El Federalista. Altibajos de amistades entre moderados y puros. Para más detalles, ver Harvey L. Johnson en Altamirano: 13, y González Obregón: xvi.
} 
los e instruyéndolos a la vez en cuestiones relacionadas con divisiones internas, guerras y los trágicos resultados para la nación.

En segundo lugar, la exclusión de capítulos y el cambio de orden y de enlaces en El fistol del diablo se debió a una decisión del autor que afectó la conclusión de la novela, dando fin a la tercera y última edición con una promesa de Payno de que la novela tendría una secuela: "Entonces publicaré otro libro, tratando de satisfacer completamente la curiosidad de los amabilísimos suscriptores" (2000b: 655). Es de suponer que el libro que Payno tendría en mente era una novela sobre la Intervención Francesa, guerra que nunca trató en su narrativa. Debido a que Payno falleció sin tener tiempo para escribir tal libro, El fistol del diablo queda ante el lector como novela de dos conclusiones: la de 1848 y la de $1887 .{ }^{8}$

En tercer lugar, de las tres novelas publicadas bajo su nombre es evidente que la novela de mayor importancia para el autor fue El fistol del diablo, manteniéndolo ocupado en varias ediciones a lo largo de más de cuarenta años, con divergencias en el estilo, cambios en la secuencia narrativa y dos conclusiones, hecho en que importa subrayar el siguiente punto:" en la obra de Payno, El hombre de la situación (1861) corresponde a una etapa estilísticamente anterior a El fistol del diablo

\footnotetext{
${ }^{8}$ Paradojas del autor: Payno escribió enormes masas narrativas que contienen varias novelas, leyendas y un sinnúmero de cuentos o relatos. Sus dos últimas novelas, sin embargo, tienen una coherencia narrativa innegable; no obstante, Payno las consideró meros (pero enormes) fragmentos.

${ }^{9}$ Aurelio de los Reyes, quien tuvo acceso a la edición de 1887, nos da detalles de suma importancia para los que nos interesamos en la organización interna de esta novela: "La versión definitiva la dividió [Payno] en cinco partes, la primera de XIX capítulos, la segunda de XX, la tercera de XIV y la quinta de XXV, y la publicó en dos volúmenes. Como queda dicho, las frecuentes alteraciones afectaron su continuidad" (Payno 2000a: 21); énfasis nuestro. De tal división en cinco partes no hay indicio alguno en la edición que manejamos; definitivamente, tal organización revelaría propósitos de Payno que determinaron el ritmo narrativo, tensión conflictiva y la composición misma de la trama novelesca. Parece haber, sin embargo, una confusión: la suma de los capítulos según la cuenta de Aurelio de los Reyes es de 78 capítulos, difiriendo de la suma total que contiene la edición que manejamos $(49+64=113)$ y que corresponde a la versión definitiva, es decir, la de 1887. En el pasaje citado hay claramente un lapso que omite — quizá por razón de una simple errata de editor- la cuarta división y el número correspondiente de capítulos. Que quede constancia, de cualquier manera, de la urgente necesidad de ediciones críticas de la narrativa mexicana del siglo xIx.
} 
(en su edición final de 1887), y relativamente distante en relación a Los bandidos de Río Frío, novela que Payno publicó tres años antes de fallecer. Es decir, entre los años 1886-1891 — tiempo en que está fuera del país como cónsul en ciudades de Espańa y Francia- Payno reescribe El fistol del diablo, y luego escribe en su totalidad Los bandidos de Río Frío, novela que ha sido considerada como "el estudio costumbrista más amplio que existe en la literatura mexicana”. ${ }^{10}$ En 1892 Payno vuelve a México con varios proyectos literarios en mente, entre ellos sus Memorias. ${ }^{11}$ Con ánimo y entusiasmo envidiables, Payno no piensa en la muerte - la cual está próxima. ${ }^{12}$

Una lectura de El fistol del diablo en nuestras circunstancias históricas — por ejemplo, la guerra de ocupación de los Estados Unidos en Irak y Afganistán - no puede limitarse a cuestiones meramente literarias, ya que paralelos históricos de ocupación militar pueden ser fuentes de una mejor comprensión de novelas con una temática similar. ${ }^{13}$ Reunamos

${ }^{10}$ Véase Payno 2001: ix. La crítica literaria ha estado conforme con la clasificación de la narrativa de Payno dentro del costumbrismo hispano, clasificación que reduce su importancia literaria y que tratamos de corregir en el presente estudio.

${ }^{11}$ Extremos liberales: Juan Díaz Covarrubias publica Gil Gómez el Insurgente en 1858 a los 21 años de edad; en la conclusión promete una secuela: "Más adelante, volveremos a encontrar en otras circunstancias a algunos de los personajes de esta historia" (302). Desafortunadamente, a los 22 años de edad Díaz Covarrubias es pasado por las armas durante la Guerra de Reforma. Vicente Riva Palacio, quien fallece en 1896, publica su tetralogía narrativa entre 1868-1872, para luego dedicarse a la política, a la historia y a la diplomacia. De publicarse en varios tomos como una sola obra, las cuatro novelas de Riva Palacio serían comparables a El fistol del diablo o a Los bandidos de Rio Frio en extensión. En cuanto a contrastes, Payno establece su legado literario entre 1887-1891, cuando lleva a cuestas 77-81 años. Vitalidad y cosecha en pleno otońo.

${ }^{12}$ Luis González Obregón nos ha dejado este vivo recuerdo de Payno: "La última vez que vi a don Manuel Payno, fue el año de 1894 [... Residía entonces en San Ángel, y en su físico era una verdadera ruina, pues a la sazón contaba ochenta y cuatro ańos de edad y estaba casi ciego y achacoso [...] Esta última vez que le vi, su espíritu rebosaba ilusiones y abrigaba proyectos literarios. Tenía esperanzas firmes de que le operarían los ojos, de que le reducirían la hernia, de que le curarían del estómago, y de que, ya libre de dolencias y medicamentos, se consagraría a sus estudios favoritos. Escribiría sus Memorias, los recuerdos de una vida tan larga como azarosa y peregrina" (ix).

${ }^{13}$ Para correspondencias entre Manuel Payno y novelistas contemporáneos de origen mexicano, véase mi estudio en Cantú: 151-174. Alfredo Véa es un novelista chicano que participó en la Guerra de Vietnam en 1968-1969 y cuyas novelas —ante todo Gods Go Begging (1999) — son un intento de entender la esencia de la guerra en toda su sublimidad y terror, análogo al de Manuel Payno en El fistol del diablo. 
en seguida los rasgos fundamentales en la obra narrativa de Payno para mejor entender su lugar en la historia de la literatura mexicana.

En lo que sigue, proponemos un análisis de El fistol del diablo que parte inicialmente de una etnografía simbólica de objetos de valor estético — caso ilustrado en la novela de Payno con un fistol de diamante engastado-, con raíces en leyendas y en la historia literaria de varias naciones del mundo pero cuya función en la novela es la de un elemento formal que determina la composición narrativa, tanto en su esfera estética cuanto en la política de su tiempo. A un nivel formal, el fistol como objeto es un factor determinante en la composición narrativa en tanto que opera mediante un continuo cambio de dueños, por lo tanto como hilo conductor a lo largo de la narración. Ahora bien, como leyenda narrada por Rugiero (otra voz en la narración, distinta a la del narrador omnisciente-cronista), la historia del fistol muestra relaciones intertextuales con Las mil y una noches y con una temática tradicional enfocada en fallas humanas, como la tentación y la avaricia. ${ }^{14}$ De tales

\footnotetext{
${ }^{14}$ A primera vista, el Rugiero de Martínez de la Rosa no tiene obvias correspondencias con el de Payno, el cual está más próximo a un entrecruce del Fausto de Goethe con el Don Juan de José Zorrilla y con Vautrin, de Balzac. Sin embargo, al intentar un razonamiento de tal asociación de nombres — de indudable importancia para Paynonotamos sutiles lazos de unión: en La conjuración de Venecia, Rugiero es un "insurgente" (en su calidad de conjurado) quien vuelve a su tierra de origen para cumplir su destino: descubrir la identidad de su padre (Pedro Morosini) y ser ejecutado en aras de la libertad republicana. Esta cuestión tendría que ser aclarada con más detalle, algo imposible por ahora; quede por el momento una hipótesis de trabajo: la relación entre el Rugiero de Payno y el de Martínez de la Rosa se establece no en los personajes (la representación del diablo en uno, el espíritu insurgente a favor de la República en el otro) sino entre obras, es decir, intertextualmente, por lo tanto en temas basados en un retorno al hogar (Arturo a su hogar en México después de su estancia en Inglaterra), un padre desconocido (Arturo no sabe de la "conjuración" anti-republicana iniciada por su padre), la muerte por razones políticas (Arturo muere defendiendo a su patria), y, quizás de mayor sentido simbólico, el tema de la fatalidad (en la obra de Payno entendido como "la casualidad"): el "castigo" que padece México por haber traicionado los ideales insurgentes de la generación anterior (Anselmo, muerto en la pobreza, multitud de veteranos de guerra sin pensión, etc.). En un sentido amplio, la entrada del general Winfield Scott por la avenida principal de la ciudad de México — como acto final
} 
elementos tradicionales, y a raíz de hechos históricos como fue la guerra de los Estados Unidos contra México, Payno intentará modernizar - en un sentido que unifica la estética, la literatura y la política- la novela histórica en México.

En su organización formal, los pasajes en que Payno plantea los elementos ideológicos de su novela constituyen un empalme sincrónico de tres tiempos: el remoto, el pasado reciente y el presente de la narración. Asimismo, tal empalme temporal incluye tres voces narrativas, tres tiempos y tres diferentes puntos de vista: el de Rugiero (en primera persona), el de Anselmo el insurgente (en primera persona), y el narrador-cronista de la novela (con acceso a la omnisciencia a lo largo del relato). El tiempo remoto, mítico y fuente de leyendas comienza con la "Historia de una piedra preciosa" (capítulo IV, segundo tomo), leyenda con tácitos orígenes en Las mil y una noches y narrada por Rugiero en relación a la historia del fistol y sus violentos pero interesantes cambios de dueño.

La convergencia de tiempos le da un carácter absoluto, eterno, a la noción que Manuel tiene del presente, situándolo en un trance oracular del cual Manuel no tiene idea pero que el lector aprecia -incluso a un nivel tecnológico, es decir, moderno, según fue el "panorama" popularizado en el siglo XIX, con sus ilusiones pictóricas, pinturas en serie, antecedente en línea recta del arte cinematográfico-, interpretando los minuciosos detalles de la descripción como presagio o prefiguración de la catástrofe que se avecina a un nivel nacional: la guerra con los Estados Unidos ("ciudades, campos, ejércitos y pirámides"). Como instrumento artístico de una tecnología moderna, el uso del panorama - que Payno habrá visto en Francia o en los Estados Unidos

de la ocupación norteamericana - pudiera haberse interpretado por la generación de Payno como un "castigo" político a una generación que "olvidó" el legado republicano de Hidalgo y de Morelos: en efecto, al lado de las escoltas norteamericanas va Rugiero montado en un corpulento caballo: "y a los diez minutos la bandera tricolor mexicana fue arriada en el Palacio y enarbolado el pabellón de las estrellas" (Payno 2000b: 645). En cuanto al apellido "Delmotte" adoptado por Rugiero: nada tiene que ver con el personaje de Martínez de la Rosa, pero hay indicios de que Payno tenía en mente al novelista y dramaturgo belga Henri P. Joseph Delmotte (1822-1884), activo en el periodismo político de su tiempo y forjador de un teatro nacional en Bélgica con enfoque en la clase media. De nuevo, lo anterior es mera hipótesis de trabajo que, por el momento, servirá solo para sugerir la esfera internacional en que se movía el pensamiento literario de Payno. 
durante uno de sus viajes - produce un resultado que es casi "cubista" en su representación ("todo rápido, confuso, como quien ve [...] sin acertar a definir qué es lo que tiene delante"). Importa, a la vez, interpretar lo que se representa en el panorama ("ciudades, campos, ejércitos y pirámides") como una tetralogía alegórica de la Conquista de México, tanto de Tenochtitlan como del México de mediados del siglo XIX. Según veremos en seguida, se alude a ambas "conquistas" en forma simultánea, síntoma de no poder entender por completo la "conquista" de 1848 sin el acontecimiento previo, ocurrido siglos antes pero sobrepuesto continuamente al final de la novela, sugiriendo un acontecimiento intermitente, destructor, que retorna con la fuerza de lo reprimido. ${ }^{15}$

Cuando llegan los novios a la Quinta de San Jacinto, su fortuna ha mejorado: Teresa está a punto de liberarse de don Pedro, corrupto albacea que en la novela alcanza niveles alegóricos de la Espańa cerrada al progreso. ${ }^{16}$ Gracias al espíritu de empresa en Luis Cayetano, Teresa se convierte en dueña de la Quinta de San Jacinto, propiedad que representa, dentro del idilio conciliador de la novela, un nuevo espacio doméstico para la pareja criollo-mexicana, quinta que será ocupada y des-

${ }^{15} \mathrm{Al}$ no encontrar satisfactoria la tradicional problemática del argumento según su división interna (exposición, nudo y desenlace), hemos preferido la sugerida por Roland Barthes, quien divide el argumento narrativo en cuatro partes (exposición, desarrollo, stretto, conclusión), del que adoptamos la tercera categoría, definida como "a tightened section where scraps of answers rapidly come and go" (29). Se podría preguntar por qué razón el desenlace trágico comprende 23 capítulos, y hay justificación en ello; de hecho, un examen de la organización de tales capítulos revela el plan de composición de Payno después de una sección (el stretto) en que el desarrollo adquiere una obvia aceleración narrativa, con diferentes puntos de vista en las sucesivas "veladas" en la Quinta de San Jacinto y demás capítulos que contienen, en forma de fuga musical, distintas partes narrativas que convergen en un solo tema: la guerra contra los Estados Unidos. Por el momento, quede como sugerencia que el stretto funciona como transición multiforme en la que se anuncia el Apocalipsis - término entendido como revelación y fin de mundo-, ocasionado por la invasión y guerra norteamericana, según se expresa en el siguiente pasaje: "el miedo, la rabia, la venganza, el egoísmo, la avaricia, el fanatismo, la envidia, todos los monstrous terribles de las pasiones se cernían sobre la desgraciada sociedad de México [...] Pero estas figuras fantásticas y apocalípticas que solían pasar por el transparente cielo, medio veladas por las nubes del verano, no las veían ninguno de los altos personajes" (2000b: 394).

${ }^{16}$ Nótese la forma satírica con que Payno describe este personaje: "Don Pedro era cristiano viejo, retrógrado en política hasta desear el rey y la Inquisición, y primero se hubiese dejado cortar un pie que faltar a la misa de once del Sagrario" (2000b: 371). 
truida por soldados norteamericanos en el capítulo con que concluye la edición de 1887. La Quinta de San Jacinto se describe minuciosamente a lo largo del capítulo, correspondiendo a la descripción arquitectónica más detallada y simbólica de toda la novela, apropiadamente titulada "Un paseo en la Quinta de Teresa":

[P]arecía un castillo [...] lo antiguo y lo moderno estaban combinados [...] Una vez pasada la puerta y subiendo los tres escalones [...] relucía una fuente de azulejos de colores semejante a las del Alcázar de Sevilla. En el centro de la fuente un cuadrado también de azulejos remataba en un macetón colosal de donde [...] colgaban en desorden [...] multitud de serpientes de cuyos cuerpos brotaban unas flores rojas [...] Era simplemente un nopalillo, tan bien cultivado, que en cualquier jardín de Europa habría pasado por una maravilla [...] Alrededor de la fuente, unos asientos o bancos hechos con piedras de templos y edificios aztecas grabadas con indescifrables jeroglíficos (2000b: 414-415).

La descripción arquitectónica de la quinta es heterogénea, extensa, precisa, sugerente, sin duda uno de los pasajes en El fistol del diablo más revisados y pulidos por Payno, con la totalidad de la novela en mente, por lo tanto pleno de simbolismo histórico-cultural y de presagios. Por principio, el "castillo" es un juego tropológico de semejanzas, ya por representar Castilla, ya por sugerir "lo antiguo y lo moderno" de un lugar sitiado — ya sea Tenochtitlán, el Alamo, o la ciudad de México-, sincronía temporal acentuada por los "tres escalones" que se interpretan como imagen de la historia de México: el mesoamericano, la colonia, y el México independiente en transición a la modernidad. El lector se siente ante un panorama histórico de obvios entrecruces globales: España también tiene sus "escalones" culturales, los que incluyen el musulmán (Alcázar de Sevilla), tan próximo al México antiguo que de nuevo se representa como la parte central de la quinta, otro axis mundi, ombligo cósmico que es un "macetón colosal" con sus múltiples serpientes (en clara relación simétrica con Coatlicue), y con su nopalillo de flores rojas, por lo tanto de correspondencias semánticas con Tenochtitlan: el lugar de las tunas, o en sentido figurado: sitio de fundación de la ciudad azteca, con las "rojas flores" como reducción simbólica de corazones, ofrendas, sacrificios.

La idea que se deduce de este tipo de representación no equivale a un "mestizaje" o fusión de culturas, ideología asociada con el naciona- 
lismo mexicano del siglo xx. El nacionalismo de Payno es distinto: no propone una fusión, sino la conciencia de varias herencias culturales e históricas que le pertenecen al México moderno. Tal conciencia y tal "castillo" son asediados por los Estados Unidos, transformando a la quinta en otro Tenochtitlan y, por antonomasia, en otro lugar de devastación. Citemos, aunque sea en parte, la oración que concluye este capítulo: "Sentado cualquiera debajo de los majestuosos fresnos [...] imposible que creyese que la discordia, la matanza, el robo y la miseria se cernían a poca distancia sobre los habitantes del valle de México" (2000b: 418).

Dentro del largo argumento de la novela, este capítulo constituye el centro ideológico del stretto (capítulos XXXVII-XLI), presagiando el desenlace trágico en la edición de 1887. A partir de este capítulo comienzan "las veladas" en la quinta, con sus referencias a la peste en Florencia, El Decamerón de Boccaccio, y la implícita asociación con ciudades sitiadas, ora por la plaga, ora por un ejército invasor. Como centro ideológico "Un paseo en la Quinta de Teresa” es un capítulo que plantea una topografía simbólica de otro orden, a saber: la idea de un paraíso perdido, de una inocencia mancillada, condición representada de acuerdo a la oposición conflictiva entre la ciudad y el campo, la corrupción metropolitana contra la sencillez campestre, el mal contra el bien, la vida del fiel pastor (Pastor Fido) en oposición a la del hombre de ciudad, traidor en relación a todo valor humano. ${ }^{17} \mathrm{Tal}$ actitud "pastoril" quizás sea generacional, ante todo entre veteranos de guerra; en todo caso, una actitud similar aparece como centro definidor en $\mathrm{La}$ navidad en las montañas, de Altamirano, novela breve cuya descripción

${ }^{17}$ En Payno el tema de las diferencias entre corte y aldea no es meramente literario sino que contiene paralelos con la realidad nacional, confiriéndole al disfraz del "pastor fiel" un obvio giro ideológico. En Los bandidos de Río Frío, Payno contrasta la ingenuidad, belleza y honradez de Cecilia la trajinera, oriunda de la región de Chalco y bilingüe (náhuatl y español, por lo tanto quizás indígena o mestiza), junto a la valentía y lealtad de Juan Robreño, con la atmósfera ruin, fanática y malsana de los que radican en la ciudad de México (el Conde de Sauz, Relumbrón, Evaristo, entre otros). En cuanto a la realidad nacional, recordemos las descripciones de Fanny Calderón de la Barca de la belleza de mujeres indígenas que viven fuera de la ciudad y la pobreza y desaliño de gente pobre que vive en la capital; en forma específica, traigamos a la memoria su estancia en la hacienda de San Bartolo, en Michoacán, donde cree haber visto el mejor ejemplo del "carácter mexicano": "I think the Mexican character is never seen to such advantage as in the country" (481-483). 
de una vida apacible y en armonía con la naturaleza humana es representada por el hermano cura y los pastores que lo rodean con cariño y gratitud. En Payno, creemos que es precisamente en tal actitud de ironía y sátira donde se ilumina el sentido del seudónimo "Pastor Fido" (el pastor fiel) adoptado por Payno en su introducción a El fistol del diablo. ${ }^{18}$

Quizás de acuerdo con problemas sicológicos que afligen con frecuencia a veteranos de guerra, o por razones estéticas, Payno no describe en forma directa la batalla de Churubusco en la que él participó, sino de soslayo, a la distancia, con frecuencia desde el punto de vista de otra persona, por ejemplo, Juan Bolao, un personaje secundario pero sencillo y honrado. El capítulo dedicado a la batalla de Churubusco (LIX), se interpola entre las siete previas veladas en la Quinta de San Jacinto y la octava, con la cual termina el argumento en forma de catástrofe más que como resolución. Encausado en vías del desenlace trágico de la novela, este capítulo - a pesar de su título- no describe tal batalla de Churubusco con precisión y detalles, y si hay indicios de ella es como en un panorama: un batallón mexicano "sin artillería ni parque", "las compañías llamadas de San Patricio", "lanzas, sables y cascos de la caballería relucían a lo lejos”, imágenes que culminan en el párrafo final del capítulo:

Tiros de fusil y pistola se escucharon muy cercanos. Dos soldados americanos descarriados, montados en sus enormes caballos, corrían disparando tiros, y eran perseguidos por un grupo de mexicanos con el lazo en la mano. En la puerta de la quinta uno de los fugitivos fue lazado, derribado del caballo y arrastrado, dando gritos feroces en un idioma extraño (2000b: 603).

${ }^{18}$ Federico Carlos Sáinz de Robles nos recuerda que el género pastoril, creado por Teócrito, perdió su verdad precisamente en el momento de llegar a la cumbre de su popularidad en el siglo xvi ("el exceso de perífrasis y la elegancia estudiada restaron verdad a sus producciones"). Entre los escritores italianos, Sáinz de Robles incluye el Pastor Fido, de Guarini (939). Cabe subrayar la oposición implícita en la valoración de Sáinz de Robles: la verdad es el fundamento de la vida campestre y, por inversión lógica, la mentira e hipocresía se relacionan con la vida urbana, una actitud y modo de pensar no extrańos a Payno, cuyo pensamiento republicano se conjuga bien con su idea del hombre: "La sociedad que se reunía en la quinta, y que en lo general era compuesta de personas de excelente corazón, tenía, como la mayor parte de los humanos, sus tendencias a la ingratitud y al egoísmo" (Payno 2000b: 593). 
La descripción de la batalla de Churubusco obtiene un grado mayor de dramatismo en el tiempo presente, índice de un tiempo congelado, eternizado en un momento histórico, aunque no en sitio sino desde el punto de vista de Juan Bolao ("que subía al mirador") desde la Quinta de San Jacinto, lugar campestre y de vida pastoral ahora asediado por el enemigo. El desastre está próximo. Lo que parece a primera vista una escena de aparente intento humorístico de parte de Payno (los dos soldados americanos disparando tiros, "perseguidos por un grupo de mexicanos con un lazo en la mano"), al contrario acentúa dos puntos: en primer lugar, la superioridad en armamentos modernos del ejército de los Estados Unidos junto al valor del soldado mexicano (en el capítulo LXIII, titulado "La fuga", el narrador-cronista comenta: "los mexicanos [...] son incansables en la guerra. Los derrotan hoy, y al día siguiente aparecen luchando otra vez como si nada les hubiese sucedido"); en segundo lugar, un paralelo que a Payno no se le habrá ocultado, razonamiento del siglo XIX en relación a la conquista de Tenochtitlan: la superioridad tecnológica en las armas de Hernán Cortés y sus soldados, en ocasiones perseguidos por guerreros aztecas con macana y mecate en mano.

El argumento de la novela acelera su ritmo a partir de este capítulo hasta llegar al penúltimo, titulado "La fuga", en el que el "panorama" exhibe su fuerza descriptiva como estilo narrativo. La perspectiva se establece de nuevo desde la Quinta de San Jacinto ("[Bolao] subió al mirador y observó la ciudad como en fuego. En la oscuridad de la noche se distinguían las llamas de un incendio y se veían los relámpagos rojos que formaban los tiros de los fusiles" [2000b: 646]), proyectando por medio de imágenes apocalípticas una realidad infernal y un fin de mundo que traen a la mente no solo el desplome de Tenochtitlan como civilización, sino la destrucción de Roma por la barbarie del norte, por consiguiente como consecuencia de una guerra basada en diferencias religiosas y culturales. En estos pasajes narrativos, Payno luce magistralmente su poética de la novela, según fue expuesta en la introducción de Pastor Fido, poética que depende a la vez de una "buena dosis de entusiasmo y de pasión".

Ebrios, blandiendo espadas y largos cuchillos, con grandes pistolas ceñidas en la cintura, jurando y gritando en lenguas ásperas y extrańas, con 
las caras encendidas, las cabelleras y barbas rojas y flotando en desorden, pesadas botas hasta los muslos y blusas encarnadas, se creería que eran los descendientes de los cimbrios y vándalos que invadieron a Roma en otros siglos. Eran los voluntarios de Indiana [...] y los rangers texanos del general Lane, todos gente bárbara de todas las regiones del mundo (2000b: 647). ${ }^{19}$

Payno lleva al lector al centro de la ciudad de México para que sea testigo de lo que el hombre es capaz cuando se trata de herir, matar o destruir, con ciudadanos y ejército mexicanos repitiendo en la historia lo hecho por aztecas de antaño, defendiéndose y confirmando en una guerra a muerte la convicción en aumento de su destino no solo como nación, sino como civilización. La relación sincrónica de acontecimientos históricos - la conquista de Tenochtitlan, la Guerra de Independencia, la invasión norteamericana- se entienden por medio de una estética de la sublimidad en la obra de Payno, es decir, en los límites mismos de la representación literaria cuya insuficiencia discursiva es incapaz de dar expresión a lo inconcebible: la mortandad y devastación en la ciudad de México durante la guerra contra los Estados Unidos. Esta misma sublimidad artística es lo que facilita en Payno el uso del "panorama", utilizado en distintas partes al final de la novela, incluso en relación al sitio de Tenochtitlan de acuerdo a 1) diferencias tecnológicas en las armas ("en armas somos muy inferiores. Esos rifleros de Missisipi, son peor que el mismo demonio [...] mientras nuestros soldados tiran un balazo ellos disparan diez"); 2) anacronismos históricos en los que la repetición es tácita ("se atrevían a hollar con su inmunda planta la capital de Moctezuma"; "el general Xicoténcatl, con casi todo su batallón, pereció en el bosque"); 3) desde una perspectiva mesoamericana ("el triste espectáculo que presenta una población numerosa que va a ser tomada a sangre y fuego"), amenaza militar que se visualiza como

${ }^{19}$ He aquí la poética de la novela, según Payno: "La novela, la buena novela es, como el drama, una de las obras más laboriosas y difíciles del entendimiento humano. La novela de largo aliento es la acción, la vida, la pintura, la filosofía, la fotografía; mejor dicho, todo junto. Entran en su composición multitud de conocimientos, observaciones muy prolijas, y siempre una buena dosis de entusiasmo y de pasión de parte del autor" (2000a: 40). En cuanto a la novela de largo aliento, ver lo que corresponde al epílogo ("Cosas de otro tiempo", capítulo LXIII) en Los bandidos de Río Frio: "Con este material escaso [...] formé la trama y he escrito esta novela, no de largo, sino de larguísimo aliento" (2001: 727). 
imagen en oposición de agua + fuego, difrasismo náhuatl que significa agua quemada (atl tlachinolli), es decir, una guerra a muerte, a sangre y fuego; 4) la angustia de ver a hermanos aliados del invasor ("un tropel de contraguerrilleros traidores [...] gritando ‘Muera México!'”), asociados por la memoria histórica con Tezcoco unido a las huestes de Hernán Cortés; y, por fin, 5) la catástrofe final: "la conquista de la capital está consumada" (2000b: 644; para las demás citas: 542, 556, 587, 605, 648-649 y 640, respectivamente).

En El fistol del diablo Payno construye un argumento o trama que abriga una rencilla entre naciones que se remonta a la guerra de Texas, con memoria de El Alamo y la batalla de San Jacinto en la que el general Santa Anna es sorprendido y vencido por Sam Houston. La historia se repite, por lo tanto, en dos planos: el asedio de Tenochtitlan por Hernán Cortés, y su paralelo histórico en El Alamo con Santa Anna al mando. Por razones de lógica narrativa, Payno reemplaza El Alamo con la Batalla de San Jacinto, en la que Santa Anna es vencido. El asedio de la ciudad de México y, por relación metonímica, la Quinta de San Jacinto, serán, en forma implícita, repeticiones de lo acontecido en El Alamo, pero en forma inversa: ahora es el ejército norteamericano el que ataca la "fortaleza" mexicana. Una lectura atenta de esta sincronía histórica nos permite apreciar el rigor con que Payno organiza en dos partes o tomos la edición de 1887.

En efecto, es en el primer capítulo del segundo tomo donde el lector tiene conocimiento de que tanto Manuel como Valentín acompañaron a Santa Anna a "la campaña de Tejas, hasta que aconteció la derrota de San Jacinto, de donde se retiraron a pie, habiendo llegado a las villas del norte" (2000b: 12). Luego se indica que fue durante un viaje por el norte que Manuel se enamoró de Teresa, ligándose en tal coyuntura la idea de campañas de guerra y de amor, en directa simetría con las de Arturo. Nuestro interés, por ahora, es el diseño irónico que se establece entre la derrota del ejército de Santa Anna en San Jacinto, y la etapa final de la guerra de 1847 en México, la cual culmina en El fistol del diablo precisamente en la Quinta de San Jacinto, donde se repite en forma simbólica lo acontecido en El Alamo. En el pasaje citado, son los voluntarios de Indiana y los rangers texanos los que representan la barbarie y el caos, conocidos por un racismo anti-mexicano que ha sido documentado en la historia: 
When a band of Kentucky volunteers shot a 12-year-old Mexican boy "for sport" as he worked in a cane field [...] Taylor merely reprimanded the culprits $[\ldots]$ in some of the volunteer units, especially the Texas Rangers, Taylor recognized not just Barbour's "devils," but tough men who would fight like proverbial devils (Stevens: 145).

Payno, por lo visto, decidió asociar o sobreponer dos catástrofes mexicanas: la causada en México por los Estados Unidos - cuya entrada triunfal en la capital es dirigida por el diablo ("Rugiero venía al lado del capitán Americano", en el capítulo "La fuga”)_, y la relacionada con el general Antonio López de Santa Anna - desde las causas bélicas en El Alamo y en San Jacinto, hasta el efecto histórico en la ocupación norteamericana de México-, lo que explica la representación francamente negativa de Santa Anna en esta novela de Payno. No tenemos noticias de que Santa Anna haya leído El fistol del diablo, sin embargo no se le ocultó la crítica del novelista: Luis González Obregón nos informa que en 1853 Payno es perseguido por Santa Anna, obligándolo a refugiarse "en los Estados Unidos" donde reside hasta 1854, año en que Payno vuelve a México para tomar parte "en la revolución de Ayutla, tanto porque era contrario de Santa Anna cuanto por su amistad con Comonfort" (xiv-xv).

Concluyamos nuestro estudio con una reflexión sobre el estilo y la unidad estructural de El fistol del diablo. Recordemos que el capítulo inicial comienza con imágenes del paisaje mexicano ("Este cielo azul, estas flores"), seguidas de metáforas de guerra, libertinaje y pactos con el diablo. Imágenes y tropos de dicción similares —a veces idénticos— aparecen en las descripciones de la Hacienda de la Florida y de la Quinta de San Jacinto, repitiéndose en el último párrafo de la edición de 1887, justamente en la mañana posterior a la destrucción de la misma quinta en manos de los voluntarios de Indiana y Texas.

El cielo estaba azul y puro, y el sol espléndido y risueño, bañaba con su alegre luz de oro las caras abotagadas y los cabellos rojizos de los voluntarios $[\ldots]$ Fueron sucesivamente despertando, y levantándose, y miran- 
do asombrados las bellezas del jardín que acababan de destruir, pero su instinto les hizo dirigirse de nuevo a la despensa a buscar licores [...] Los cantores pajarillos que habitaban la copa de los fresnos, ahuyentados con los tiros, el ruido y la pólvora de la noche [...] regresaban rápido a la espesura de la sierra verde y tranquila, donde no había penetrado todavía esa terrible fiera que se llama hombre (2000b: 654).

La noche del ataque a la Quinta de San Jacinto -el 16 de septiembre de 1847, día y mes de importancia nacional en México- los rangers de Texas y voluntarios de Indiana ven frustrados sus varios intentos de entrar en "el fuerte", hasta que dan "al fin con la ventana del costado, por cuya reja había subido Rugiero" (2000b: 652; énfasis nuestro). ${ }^{20}$ La unidad artística sugerida por estas referencias a costados, diamantes, cuevas, volcanes, pirámides, montańas, fieras, la avaricia, ejecuciones y el diablo, desarrollan un nexo ideológico de interés cuando nos damos cuenta de una de las intenciones de Payno al reescribir su larguísima novela: la de estructurarla según principios artísticos abiertos a la política e imaginación histórica del autor.

De hecho, en una cultura como la mexicana de mediados del siglo XIX, en que predomina la iconografía y símbolos tradicionales del catolicismo, la Crucifixión es de importancia fundamental, entendida a lo largo de El fistol del diablo a nivel de sinécdoque, es decir, de la parte por el todo: la herida en el costado por el Cristo crucificado, la montaña o pirámide por el Gólgota y, entre otras permutaciones, la cueva por la tumba. Concordando con tal iconografía y simbolismo tradicionales, pudiérase proponer el nacimiento de un nuevo calendario, una nueva era, marcada por tal acontecimiento, como es el caso en naciones cristianas, calendario simbólico de obvias analogías tanto con el pensamiento revolucionario francés - fuente de inspiración del liberalismo mexicano- como con el concepto cíclico mesoamericano de distintos soles, diferentes eras, rituales de renovación del fuego, creaciones en serie con sus respectivos tipos de humanidad y fin de mundo. Vista desde ese posible ángulo interpretativo, El fistol del diablo postularía la guerra con los Estados Unidos como un fin del mundo, destrucción de sus habitantes anteriores, y el principio de otro mundo y de una

\footnotetext{
${ }^{20}$ En el texto, la fecha que se da es "del día 16 de septiembre de 1846", pero se trata de una evidente errata de imprenta; en un pasaje anterior (643), Payno da la fecha del 15 de septiembre de 1847 .
} 
distinta humanidad. El hecho de que el desenlace trágico (en la edición de 1887) se componga de 23 capítulos más un epílogo (por lo tanto 24 secciones narrativas), quizás no sea fortuito o de mera casualidad, correspondiendo por lo contrario a la cifra asociada con una totalidad temporal, un tiempo cósmico que, por medio de una unidad temporal de 24 horas, mantiene su periodicidad con sus días y sus noches, con sus momentos de oscuridad y de luces en continua rotación. Esta visión trágica, casi mítica, de Payno, se expresa por medio de Rugiero, quien reflexiona sobre el carácter del hombre según su ejemplo "en las inmensas Américas", opinando lo siguiente: "éste es el país donde se presenta la raza blanca en toda su barbarie, la raza latina en toda su locura, y la raza indígena primitiva con toda su incomprensible rareza y su extraña civilización" (2000b: 67).

La guerra con los Estados Unidos produce en Payno un paralelo con la historia colonial de México: de una jerarquía colonial de castas, Payno ahora piensa en términos de una tipología racial o étnica, pirámide invertida con la "raza blanca" en obvia relación con los Estados Unidos (por lo tanto, representación de la barbarie), seguida del legado de la Nueva España, con su locura (latina) e incomprensible rareza (mesoamericana), asociada esta última — por inferencia lógica — con la única civilización (aunque incomprensible) en las Américas.

La noche de Chapultepec - montańa con asociaciones mesoamericanas y, a partir del 13 de septiembre de 1847, con la derrota de Méxicose funde en El fistol del diablo con la noche de Churubusco, batalla que ha pasado a la historia como una de las más sangrientas e importantes de tal guerra. En efecto, la guerra contra los Estados Unidos concluye un 13 de septiembre en la batalla de Chapultepec, pero la unidad poética de la novela señala otro sitio y otra fecha: la Quinta de San Jacinto, el 16 de septiembre, concordando en su configuración simbólica con una topografía idealizada y una fecha traicionada a un nivel político: es decir, la discordia y divisiones en el ejército mexicano durante la guerra contra los Estados Unidos son síntoma de lo olvidado que estaban los principios políticos de la insurgencia en México. Esta sobriedad y escepticismo históricos - modernos por su crítica a la nación- logran su expresión en El fistol del diablo en forma artística, moderna y a la vez hondamente tradicional, de vínculos intertextuales con novelas, leyendas y cuentos de todo el mundo, pero con un enfoque en la realidad histórica de la nación. 
En forma paralela, Los bandidos de Río Frío concluye con el sitio de una "fortaleza" (la Hacienda del Conde del Sauz en Durango), pero en vez de otro Álamo, Payno invierte la historia de la conquista de Tenochtitlán: ahora la hacienda es una ciudad sitiada por comanches y su dirigente, Mangas Coloradas. La trama narrativa, dividida en dos corrientes anecdóticas —el amor entre Juan Robreño y Mariana, por un lado, y la recuperación legal de los terrenos de Moctezuma III, por el otro- tienen un desenlace feliz: las relaciones desiguales entre Juan y Mariana se resuelven al final, concluyendo con el restablecimiento familiar (se descubre la identidad de su hijo Juan, ahora reintegrado en la familia). ${ }^{21}$ En cuanto a tierras indígenas, después de largos ańos de litigios, Moctezuma III recupera al fin sus propiedades. Con la muerte del Conde del Sauz - quien violentamente se opuso a lo largo de la novela a los amores de su hija Mariana con Juan Robreño por ser hijo de su administrador- Mariana despierta de su "locura" y, al recobrar a su esposo y al desaparecido hijo, dice sentirse "una nueva mujer, y que la antigua habia desaparecido con la memoria de todos los dolores" (Payno 2001: 716; énfasis nuestro). En cuanto a los terrenos indígenas robados por la familia Melquíades, al ser restituidos por la ley a sus verdaderos dueños, se señala de esa manera el fin de una dinastía criolla, cambio histórico del que "se levantaba espléndido y brillante el [reinado] de Moctezuma III” (728).

Si recordamos que la edición de El fistol del diablo es de 1887, y que la de Los bandidos de Río Frío de 1891, podemos deducir que en sus últimos años de vida, Payno concibió y planteó su idea del proceso histórico nacional en el que la tradición mexicana y la modernización nacional logran al fin una periodicidad temporal que hoy entendemos como diferentes etapas nacionales: el México antiguo, la Nueva España, el México independiente -en ocasiones ocupado por los Estados Unidos y Francia- y el México moderno. En sus años postreros, de pasmosa creatividad literaria, Payno entendió con angustia y resignación que en México la misión de cada etapa nacional es destruir la anterior. Payno no se equivocó: a pocos años de su muerte, la Revolución de 1910 destruyó los fundamentos socio-culturales que legitimaron la dictadura de Porfirio Díaz.

${ }^{21}$ Véase Glantz: 96-101. 


\section{BiBLIOGRAFÍA}

Altamirano, Ignacio Manuel. La Navidad en las montañas. Reproducción facsímile del manuscrito y de la primera edición. Prólogo de Marte R. Gómez e introducción de Harvey L. Johnson. México: Manuel Porrúa, 1972.

Barthes, Roland. S/Z. An Essay. Trad. Richard Miller. New York: Hill and Wang, 1974.

Calderón de la Barca, Fanny. Life in Mexico. New York: Kessinger Publishing, 2010.

Cantú, Roberto. "Images of War and Combat in Alfredo Véa's Narrative Trilogy, 1993-1999”, en Violence and Transgression in World Minority Literatures. Ed. Rüdiguer Ahrens et al. Heidelberg: Universitätsverslag, 2005.

Díaz Covarrubias, Juan. Gil Gómez el Insurgente. México: Editorial Planeta De Agostini, 2004.

Fuentes, Carlos. La gran novela latinoamericana. México: Alfaguara, 2011.

Glantz, Margo. "La metáfora del niño expósito en Los bandidos de Río Frío", en Merlin H. Forster y Julio Ortega (editores). De la crónica a la nueva narrativa mexicana. México: Oasis, 1986.

González Obregón, Luis. "Prólogo" a El hombre de la situación / Retratos históricos. México: Editorial Porrúa, 1992.

Payno, Manuel. El hombre de la situación / Retratos históricos. México: Editorial Porrúa, 1992.

Payno, Manuel. El fistol del diablo, tomo 1, en Obras completas, vol. VI. Presentación de Boris Rosen Jélomer. Prólogo de Aurelio de los Reyes. México: Consejo Nacional para la Cultura y las Artes, 2000a.

Payno, Manuel. El fistol del diablo, tomo 2, en Obras completas, vol. VII. Presentación de Boris Rosen Jélomer. Prólogo de Aurelio de los Reyes. México: Consejo Nacional para la Cultura y las Artes, 2000b.

Payno, Manuel. Los bandidos de Río Frío. México: Editorial Porrúa, 2001.

Riva Palacio, Vicente. Monja y casada, virgen y mártir. México: Editorial Océano, 2001.

SÁinz de Robles, Federico Carlos. Ensayo de un diccionario de la literatura, tomo I. México: Aguilar, 1949.

Stevens, Peter. The Rogue's March: John Riley and The St. Patrick's Battalion, $1846-$ 1848. Washington, D. C.: Brassey's, 1999. 